\title{
EDITORIAL
}

\section{DOSSIÊ PRÁTICAS NAS IES DE FORMAÇÃO DE PROFESSORES (INICIAL E CONTINUADA) PARA A EJA}

O reconhecimento da educação de jovens e adultos (EJA) como um campo diverso, em documentos legais nacionais e internacionais, e pela comunidade de pesquisadores e profissionais tem significado poder demarcar e enfrentar especificidades que se relacionam com a multiplicidade de sujeitos e de práticas de aprendizado ao longo da vida. Instituições de Ensino Superior (IES), ao serem desafiadas a desenvolver processos de formação de professores tanto inicial quanto continuada para responder a diversidade do campo no que respeita a diferentes formas de aprender e de produzir saberes e conhecimentos, ajudaram a compor este dossiê, que resgata e compartilha trabalhos de pesquisadores brasileiros de várias regiões do país e do exterior, promovendo diálogo e aprofundamento sobre práticas formadoras para o campo da EJA.

Um dos debates centrais nesse campo se manifesta na tensão entre perspectivas que enfatizam as similitudes dos sujeitos e aquelas que procuram atender as múltiplas dinâmicas associadas às identidades raciais, étnicas, de gênero, de necessidades especiais, entre outras. A relevância desta tensão se manifesta em diferentes concepções sobre como determinar políticas e abordagens pedagógicas, visando ao direito à educação dos cidadãos jovens e adultos. Esses debates têm reflexo e também refletem tensões políticas e pedagógicas entre os profissionais do campo da EJA. Baseadas em pesquisas anteriores, sabe-se que essas diferenças não se manifestam nos discursos dos educadores de forma homogênea e sem contradições, porque expressam também posicionamentos pedagógicos e políticos de professores formadores que atuam na EJA nas diversas instituições de educação superior.

A Resolução 02, de 1 jul. 2015, do Conselho Nacional de Educação (CNE), na sua ementa, define as Diretrizes Curriculares Nacionais para a formação inicial em nível superior (cursos de licenciatura, cursos de formação pedagógica para graduados e cursos de segunda licenciatura) $e$ para a formação continuada. Essa definição passou a ser o novo marco legal para a formação de professores, dispensando versões anteriores em que esta formação acabava por ser quase um apêndice dos cursos de bacharelado, considerados - estes sim - as "verdadeiras" finalidades em 
muitos campos profissionais de nível superior. Se a Resolução em vigência - que vem produzindo revisionamento dos cursos existentes, como orientando pelo texto homologado - conseguir operar mudanças efetivas nos modos de pensar a formação inicial e continuada, pode-se afirmar que se consolida uma esperança recorrente nos pesquisadores, porque se passa a dar mais crédito e legitimidade à formação de professores, do que historicamente se tem feito. E mais: associa-se à formação inicial uma perspectiva de formação continuada que, para além das conhecidas respostas lato e stricto sensu - aperfeiçoamento, especialização, mestrado e doutorado -, traz a compreensão de que continuada deve ser a formação em segunda licenciatura e a formação pedagógica para quem domina um campo de saberes, mas não detém a concepção do que é ser professor, produzida em diálogo com as próprias concepções construídas nas vivências formais ao longa da vida escolar.

Nessa perspectiva de formação, a Resolução não exclui qualquer sujeito, e reafirma a formação de professores diversos para a prática pedagógica com sujeitos também diversos, o que inclui toda e qualquer ação educativa, nos múltiplos espaços em que se educa, na sociedade. A EJA, portanto, vê-se bastante contemplada com a cuidadosa discussão do relator no Parecer que acompanha a Resolução, porque toda a diversidade que tem proclamado ao longo das inúmeras disputas travadas em defesa do direito à educação para sujeitos jovens, adultos e idosos, nos múltiplos espaçostempos em que se situam e onde contextualizam suas existências, passa a ser organizadora de uma concepção de formação em que a prática e o estágio têm lugar relevante nos cursos de licenciatura.

O dossiê sobre práticas de formação de professores de EJA, nas IES, portanto, em boa hora será publicado, podendo contribuir para as múltiplas discussões que os cursos de pedagogia fazem entre todos os das demais licenciaturas -, na corrida contra o tempo para cumprir as exigências legais exaradas pela Resolução.

Reuniu-se, para isto, neste dossiê da Teias, premiado por um Edital da ANPEd em parceria com a Secadi/MEC, um conjunto de autores, todos pesquisadores que, à conta de suas temáticas específicas, atuam também como formadores de professores, seja em processos de ensino, de extensão e de pesquisa.

Assim, a discussão do primeiro artigo que abre o dossiê leva em conta que, se nossa carência até então tem sido de formação específica para a EJA, vale a pena conhecer o que vem acontecendo com cursos de pedagogia no Estado do Rio de Janeiro. Os cursos de pedagogia nesse estado são o 
foco da investigação proposta por Sandra Regina Sales e Gustavo E. Fischman, ao realizarem uma revisão das grades curriculares dos cursos e ao desenvolverem entrevistas em profundidade com professores que ministram disciplinas sobre EJA em IES públicas e privadas sediadas nesse estado. Partindo da premissa de que a EJA constitui um sistema historicamente impactado por circunstâncias adversas que afetam negativamente a alunos e educadores e, sobretudo, aos mais vulneráveis, demonstram algumas ideias que persistem na EJA, o que Paul Krugman (2014, p. 3) rotulou de "ideias zumbis", fortalecidas por meio de rápidos processos automáticos de pensamento corretamente errados. Mostrando como essas ideias "deveriam ter sido mortas pela evidências, mas se recusam a morrer", os autores apresentam alguns resultados relacionados à dicotomia teoria/prática. Sugerem que a mudança nos modelos de relacionamento entre cursos de pedagogia e as escolas não é uma tarefa simples, mesmo diante das evidências sobre o potencial transformador do estabelecimento de relações de colaboração e intercâmbio entre uns e outras, sempre que se abandona a clássica divisão do trabalho pedagógico que atribui à universidade a formação teórica e às escolas o espaço da "prática".

Em continuidade a esse texto tão instigante, apresentam-se Jane Paiva e Fátima Lobato Fernandes, que problematizam concepção de currículo de formação como produção cotidiana, decorrente de práticas de formação inicial de professores para os anos iniciais do ensino fundamental e para múltiplos espaços sociais e educativos, enfatizando os sujeitos jovens e adultos nesse processo de formação. Discorrem sobre a proposta de um curso de pedagogia implantado desde 2003 na Universidade do Estado do Rio de Janeiro (UERJ), demonstrando os fundamentos que sustentaram o desenho do curso, disputado na arena política de formadores e dos pensares cotidianos, avançando epistemologicamente no fazer da formação.

Com o título de “30 anos de EJA na UFMG - extensão, formação e pesquisa”, Leôncio Soares descreve e analisa um conjunto de ações que, desde a década de 1980 desenvolveu-se, especialmente voltadas para a educação de jovens e adultos, incluindo atendimento a funcionários que trabalhavam na Universidade; a habilitação em educação de adultos no curso de Pedagogia; e o início de uma linha de pesquisa na pós-graduação. $\mathrm{O}$ autor relata a passagem de muitos estudantes de diversas licenciaturas que vivenciaram a iniciação à docência, em especial, na educação de adultos, e que seguiram esse caminho na profissão, assim como muitos se fizeram pesquisadores no campo. 
Tratando de "Currículo da EJA, saberes e vivências dos professores: reconfigurações em uma escola de assentamento", Divoene Pereira Cruz e Rosa Aparecida Pinheiro problematizam a formação continuada, na articulação de saberes e vivências de professores atuando em uma escola pública municipal de um assentamento, em Florânia (RN). As autoras, valendo-se da metodologia da pesquisa colaborativa, refletem sobre a existência de duas lógicas que orientam a configuração curricular nessa escola: a oficial, da secretaria municipal de educação, e a outra referente às sistematizações e concepções epistemológicas do Movimento Social dos Trabalhadores Rurais Sem-Terra (MST). Disputas e tensões reconfiguram uma proposição curricular que contempla as necessidades dos jovens e adultos assentados.

Três pesquisadoras - Edna Castro de Oliveira, Elizangela Ribeiro Fraga e Tatiana de Santana Vieira - refletem sobre os achados de uma pesquisa qualitativa que tomou por base a formação inicial de educadores mediados pela disciplina Movimentos sociais e educação de jovens e adultos (MSEJA), visando à formação acadêmica e política dos estudantes do curso de pedagogia da Universidade Federal do Espírito Santo. O texto, intitulado EJA movimentos sociais e formação inicial de educadores na universidade, problematiza a base teórica integrada por estudos sobre dimensões conceituais dos movimentos sociais e da EJA, na relação com a práxis na formação de professores. O desenvolvimento da metodologia é um convite à leitura e aos pontos de chegada das autoras.

Adriana Cavalcanti dos Santos, Marinaide Lima de Queiroz Freitas e Valéria Campos Cavalcante são as autoras do artigo "Formação inicial e continuada do professor da educação de jovens e adultos: práticas e saberes gerados entre universidade-escola". Em processo de pesquisaformação, organizado em rede de colaboração firmada pelo Observatório da Educação, com financiamento da Capes, durante quatro anos, o diálogo travou-se entre professores da Universidade Federal de Alagoas, professoras de EJA e estudantes do curso de pedagogia, sobre práticas de ensino da leitura observadas e (res)significadas por meio de sessões de reflexão e de estudo, em escolas públicas de Maceió (AL).

Afirmando que a educação de jovens, adultos e idosos enfrenta muitos desafios para se consolidar como modalidade de educação, como política pública e como direito humano fundamental, face aos condicionantes históricos, políticos e sociais que se impõem aos estudantes, a professores e a gestores educacionais, Georgina Negrão Kalife Cordeiro, Joana d'Arc de 
Vasconcelos Neves e Salomão Antônio Mufarrej Hage, da Universidade Federal do Pará apresentam-nos a experiência de um curso de pós-graduação lato sensu. No texto "Educação de jovens e adultos e formação de professores: reflexões sobre os desafios para a sua consolidação na Amazônia paraense", os autores aproximam-nos de um outro contexto de formação, inspirado no legado freireano e na premissa de que a EJA é um território em disputa pela afirmação da diversidade e garantia de direitos humanos e sociais.

O artigo "Permanência escolar, memória e autoria: uma proposta de formação continuada da UENF para docentes de Educação de Jovens e Adultos”, de autoria de Gerson Tavares do Carmo, apresenta reflexões sobre proposta de formação oferecida pela Universidade Estadual do Norte Fluminense Darcy Ribeiro (UENF) realizada no biênio de 2013-2014 na cidade de Itaperuna localizada na região Noroeste Fluminense do Estado do Rio de Janeiro. Tomando como base resultados de pesquisa realizada na região, que indicou ser o professor determinante para a permanência escolar, o trabalho aborda o reconhecimento social docente por meio de suas memórias pedagógicas e escritas.

Atravessando o Atlântico, e sob a responsabilidade da pesquisadora da Universidade de Rouen, França, Stéphanie Gasse, a experiência de "Formação de profissionais para a educação de jovens e adultos na África Subsaariana: o desafio de um mestrado universitário francófono a distância" nos é apresentada, mostrando como, desde 1996, um mestrado profissional em educação atua na formação continuada de professores para a EJA, dessa região africana. A demanda de formação a distância, com o concurso de agências francófonas impulsionou a Universidade de Rouen a desenvolver outras relevantes parcerias, ampliando a oferta de vagas e reforçando os dispositivos existentes. O Oeste da África francófona, com a disponibilização de bolsas de estudos e a abertura para um novo público é o foco do artigo da pesquisadora, que trata de novas problemáticas na formação de professores a distância, entre elas a de preparação de especialistas polivalentes para o desenvolvimento de projetos no campo das políticas territoriais de EJA.

Em "Conceitualizando profissionalização entre os professores de adultos no contexto europeu", Marcella Milana, da Universidade de Milão e Oleksandra Skrypnyk doutoranda da Universidade do Sul da Austrália. trazem olhares estrangeiros que se somam às perspectivas adotadas entre nós para a problematização da educação de adultos. Abordando o tema da profissionalização, discutem como a perspectiva tem sido afetada por mudanças sócio-políticas e 
como o conceito é complexo, devido à vastidão e a suas peculiares características. As autoras sugerem que a profissionalização, entre professores de educação de adultos, deve ser avaliada não pela visão restritiva sobre a ocupação específica dos adultos, mas à luz dos conhecimentos que esses profissionais detêm sobre teorias de aprendizagem de adultos; sobre a epistemologia ética que orienta seu comportamento; e sobre o grau de confiança que inspiram nos alunos adultos.

Eis um dossiê que nos parece imprescindível, neste momento histórico em que se descortinam novas possibilidades de reformulação de cursos de licenciatura para a formação de professores. Nada mais oportuno para situar a necessidade - e o direito à educação ainda tomado como uma ideia zumbi na EJA - de se pensar contextualizadamente sujeitos jovens, adultos e idosos de todos os matizes.

Demover essas ideias implica pensar, portanto, como fazer práticas de formação inicial e continuada, tendo em vista a realidade e a diversidade desses sujeitos em toda a sua complexidade, dispersão geográfica, socioeconômica e cultural nos territórios afetados pelos perversos níveis educacionais que ainda os mutilam. Mutilações que afetam tanto a possibilidade de vivenciar a condição de dignidade humana, quanto de serem partícipes de processos sociais em que podem se mover como cidadãos que leem e escrevem sua própria história e com ela produzem sua existência.

Jane Paiva e Sandra Regina Sales 